\title{
Os direitos da criança portadora de deficiência e o benefício assistencial de prestação continuada
}

\author{
Mariana de Barros Cherubim ${ }^{1}$
}

\begin{abstract}
Resumo
0 presente artigo tem a finalidade de apresentar os direitos fundamentais da criança portadora de deficiência através da exposição de aspectos da Lei $n .$. 8.069/1990 (Estatuto da Criança e do Adolescente) e das inovações trazidas quanto ao tratamento da criança. Discorrer sobre os Princípios da Proteção Integral e da Prioridade Absoluta. Abordar determinados aspectos da Assistência Social e 0 Benefício de Prestação Continuada previsto n artigo 203, V, da Constituição Federal Brasileira e regulamentado pela Lei $n .0$ 8.742/1993. Discorrer sobre a importância da concessão do benefício à criança portadora de deficiência e sobre a dificuldade de consegui-lo perante a Autarquia Previdenciária.
\end{abstract}

Palavras-Chave: Direitos fundamentais; Criança; Deficiência; Assistência social.

\section{Introdução}

Sabe-se que ao longo da história da humanidade as pessoas portadoras de algum tipo de deficiência foram segregadas da sociedade de modo preconceituoso ou até mesmo de modo caridoso, quando eram colocadas em casas de assistência ou deixadas dentro da própria casa, escondidas sob o argumento de que na verdade estavam sendo protegidas.

Felizmente, o contexto de marginalização veio mudando de forma tímida no decorrer dos séculos, e o portador de necessidades especiais passou a ser considerado à luz da lei como uma pessoa que, além de ter seus direitos assegurados como qualquer outra, merece atenção especial.

0 presente artigo tem por objetivo delinear, especificamente, os direitos da criança portadora de deficiência, bem como abordar a questão do benefício assistencial que pode ser concedido à pessoa portadora de necessidades especiais, previsto no artigo 203, V da Constituição Federal Brasileira de 1988.

Para que se possa abordar especificamente o tema da criança portadora de deficiência, é necessária a exposição sobre o Princípio da Proteção Integral e da Prioridade

\footnotetext{
${ }^{1}$ Acadêmica do 50 ano de direito da UEL.
} 
Absoluta, esculpidos na Constituição Federal no artigo 227 e enfatizados pelo Estatuto da Criança e do Adolescente.

Apresentar-se-á o conceito do termo "portador de deficiência" e passar-se-á à análise do benefício assistencial regulamentado pela Lei n. 8.742/93 e previsto no artigo 203, IV da Constituição Federal.

Analisar-se-ão os requisitos para a concessão do benefício previsto em seu artigo 20 , quais sejam a incapacidade para a vida independente e a renda per capita da família da criança portadora de deficiência.

Encerra-se essa exposição ao demonstrar a efetividade e a importância da concessão do benefício, com a devida responsabilidade do Estado para seu cumprimento.

\section{Do princípio da dignidade da pessoa humana e os direitos fundamentais}

O princípio da Dignidade da Pessoa Humana consiste num fundamento do Estado Democrático de Direito, conforme artigo 1이 III da Constituição Federal.

Esse princípio compreende 0 absoluto respeito aos direitos fundamentais do homem, assegurando condições dignas de existência para todos.

Por sua vez, os direitos fundamentais compreendem uma série de direitos garantidos constitucionalmente que recebem esta nomenclatura por se tratarem de direitos considerados indispensáveis à pessoa humana.

Tais direitos foram colocados na Carta Magna antes mesmo da organização do próprio Estado, o que representa sua importância para o ordenamento jurídico bem como 0 dever do Estado em não só protegê-los, mas em buscar concretizá-los (PINHO, 2008, p. 68/69). Importante esclarecer também que o termo "direitos fundamentais" é gênero, sendo que os direitos individuais, coletivos, sociais, nacionais e políticos são espécies daquele.

A este artigo interessa destacar como exemplo de direitos fundamentais o direito à vida, previsto no caput do artigo 50 da constituição Federal Brasileira.

Como se discorrerá a respeito de tais direitos, é de fundamental merecimento destacar as principais características dos direitos fundamentais apreciados constitucionalmente. Vale dizer que são direitos inalienáveis, pois são intransferíveis e inegociáveis. Além disso, são irrenunciáveis, posto que ninguém pode abrir mão de possuir 
tais direitos. São também imprescritíveis, universais - atingem a todos os seres humanos e limitados, sempre que houver embate entre direitos fundamentais.

Portanto, temos que o princípio da dignidade da pessoa humana busca efetivar o cumprimento de todos os direitos fundamentais do homem, para que sua existência - o seu direito à vida - seja digna, alicerçada no suprimento das condições básicas de sobrevivência com qualidade.

A vida no ordenamento jurídico brasileiro como preceito fundamental constitucional

“O direito à vida é condição básica para que se realize plenamente a pessoa humana" (VERONESE, 2006, p. 21). Além disso, a vida pode ser considerada o bem jurídico de maior relevância tutelado pela ordem constitucional, uma vez que o exercício dos demais direitos decorre de sua existência.

É direito indisponível e encontra-se previsto no art. 5ํ, caput, da Constituição Federal Brasileira de 1988, como direito fundamental. É posto como um dos pilares do Estado Democrático de Direito e do Princípio da Dignidade da Pessoa Humana.

Cabe aqui, portanto, delinear o conceito da vida como bem jurídico protegido pelo ordenamento jurídico brasileiro. Leciona José Afonso da Silva que:

[...] a vida, além de ser um direito fundamental do indivíduo, é também um interesse que, não só ao Estado, mas à própria humanidade, em função de sua conservação, cabe preservar. (SILVA, 2005, p. 200).

A vida deve ser compreendida em seu aspecto biológico, físico e espiritual, já que pode ser definida como um processo de constante transformação destes três aspectos (SILVA, 2005, p.197).

Tem início com a concepção, desde quando passa a ser protegida, e prorroga-se num processo em que o homem, como pessoa, passa a definir suas características também como indivíduo, através das mudanças biológicas e psicológicas.

Esse constante processo de transformação deve ocorrer de forma em que sejam protegidos todos os seus aspectos, pelo que a Constituição assegura outros direitos que são inerentes à vida, como o direito à integridade física e moral, à liberdade, à igualdade - seja ela material ou formal. 


\section{Os direitos da criança portadora de deficiência e o benefício assistencial de prestação continuada}

Ainda segundo as palavras de José Afonso da Silva, "a integridade físico corporal constitui um bem vital e revela um direito fundamental do indivíduo" (SILA, 2005, p. 199). Para este artigo, que tem como objetivo delinear os direitos da criança portadora de deficiência, o direito à integridade física é de suma importância, conforme se verificará ao longo desta exposição.

Partindo, então, do preceito de que a vida é um constante processo de transformação, conclui-se que "tudo o que interfere em prejuízo deste fluir espontâneo e incessante contraria a vida" (SILVA, 2005, p. 197). Assim, a Constituição Federal ocupou-se de garantir o direito à vida sobre tudo aquilo que pode desfalecer seu curso natural.

José Afonso da Silva conclui o assunto com o que chama de direito à existência, afirmando que 0 direito de estar vivo compreende 0 "direito de não ter interrompido 0 processo vital senão pela morte" (SILVA, 2005, p. 198).

Assim, para que o direito à vida seja cumprido em plenitude, é preciso garantir, também, o direito à saúde, sobre o qual se discorrerá a seguir.

0 direito à saúde

0 direito à saúde está intimamente ligado ao direito à vida. Está previsto na Constituição Federal no artigo 70, IV e de acordo com 0 artigo 23, II, é de competência da União, Estados, Distrito Federal e Municípios "cuidar da saúde e assistência pública, da proteção e garantia das pessoas portadoras de deficiência".

Este direito abrange 0 direito à integridade física e consiste no direito do indivíduo de estar e manter-se incólume. Assim, tem-se que o Estado é responsável, tanto por manter o indivíduo são, desenvolvendo políticas de saúde, como para evitar que ele se torne doente.

0 direito à prevenção de doença é, conseqüentemente, parte do direito à saúde, tema de extrema relevância para este trabalho que tem como objeto os direitos da criança portadora de deficiência.

Quanto ao tema "criança", temos na Lei oㅡ 8.069/1990 (Estatuto da Criança e do Adolescente) a proteção à saúde nos artigos 70 ao 14, assegurando 0 direito à integridade física não só da criança como também das gestantes, garantindo o atendimento pré e perinatal, condições de aleitamento materno entre outros, sem falar na triagem neonatal, 
mais conhecida como "teste do pezinho", que é garantido de forma gratuita e pode diagnosticar prematuramente e proporcionar o tratamento preventivo de doenças que podem causar deficiências, como se verá adiante no tema tipos de deficiência.

Cumpre esclarecer, ainda, que, para que haja plenitude no exercício do direito à vida, é imprescindível a garantia de outros direitos, como o direito à liberdade.

\section{Princípio da proteção integral e da prioridade}

Do princípio da proteção integral

Este princípio tem suas raízes na Declaração Universal dos Direitos da Criança, efetivada pela Assembléia Geral das Nações Unidas em 20 de novembro de 1959, cujo Princípio II dispõe, in verbis:

A criança gozará de proteção especial e disporá de oportunidade e serviços, a serem estabelecidos em lei por outros meios, de modo que possa desenvolver-se física, mental, moral, espiritual e socialmente de forma saudável e normal, assim como em condições de liberdade e dignidade. Ao promulgar leis com este fim, a consideração fundamental a que se atenderá será o interesse superior da criança.

A Constituição Federal louvou tal princípio em seu art. 227, § 3ํ, quando dispõe que é dever da família, da sociedade e do Estado assegurar à criança e ao adolescente, com absoluta prioridade, todos os direitos fundamentais do homem, elencando os aspectos que deverão ser atendidos pela proteção especial.

Posteriormente, em 1990, com a vigência do Estatuto da Criança e do Adolescente, o Princípio da Proteção Integral foi amplamente difundido, apresentado seu objetivo principal e conceito, sendo que 0 art. $1^{\text {o }}$ da referida lei dispõe textualmente sobre "a proteção integral à criança".

Na verdade, este princípio tem em vista a peculiar condição da criança (e também do adolescente) de pessoa em desenvolvimento, o que a privilegia no tratamento das questões a que está submetida.

Portanto, como bem esclarece o Princípio II da Declaração Universal dos Direitos da Criança, a proteção especial deve assegurar à criança o desenvolvimento físico, mental, moral, espiritual e social de um modo saudável. A finalidade é o alcance de uma qualidade 


\section{Os direitos da criança portadora de deficiência e o benefício assistencial de prestação continuada}

de vida satisfatória para a criança, mormente quando se trata de criança portadora de necessidades especiais.

Importante salientar que o Princípio da Proteção Integral destaca a obrigatoriedade de existência de políticas públicas voltadas para a área infanto-juvenil, considerando, justamente, as características próprias ante o processo de desenvolvimento em que se encontram as crianças (VERONESE, 2006, p. 9-10).

Sendo assim, este princípio garante que a criança seja situada como prioridade imediata e absoluta, devendo sua proteção sobrepor-se a quaisquer outra medidas, objetivando o resguardo de seus direitos fundamentais.

Por este princípio também, várias decisões nos Tribunais Federais têm sido no sentido de que os valores de preservação da vida e da integridade física prevalecem sobre o interesse patrimonial do Estado, condenando-o ao fornecimento de medicamento, próteses e o que mais for necessário para que seja assegurado o direito á saúde de forma gratuita à criança necessitada e especialmente àquela em condições especiais.

Considerando, ainda, que a fase de desenvolvimento da criança reflete diretamente da formação da personalidade e na psique que acompanhará toda a existência da pessoa, tem-se que o princípio busca garantir a passagem para a vida adulta com um mínimo de qualidade de vida, eliminado-se riscos desnecessários para o corpo físico e para a esfera psicológica dessa criança.

Quanto às crianças portadoras de necessidades especiais, este princípio garante 0 cuidado intensivo de que dependem para um desenvolvimento sadio, já que necessitam de terapias específicas, como por exemplo, de fonoterapia, fisioterapia etc.

Deve-se analisar, também, que a responsabilidade do Estado (imposta pelo princípio da prioridade e da cooperação) é muito maior quando a família não possui meios suficientes de prover o desenvolvimento adequado da criança, especialmente da portadora de deficiência.

Para Josiane Rose Petry Veronese, em não tendo a família condições de prover 0 adequado tratamento médico à criança ou ao adolescente, incumbe à Administração Pública fazê-lo (VERONESE, 2006, p. 21).

Outro aspecto importante a ser lembrado quanto ao Princípio da Proteção Integral é o fato de ter representado algo muito novo em nossa legislação pátria. É de se notar que a 
legislação anterior à Constituição Federal de 1988 e à Lei no 8.069/1990 (Estatuto da Criança e do Adolescente) tratava-se apenas de uma política assistencialista que se preocupava tão somente com a situação do "menor" abandonado e infrator.

A revolução legislativa deu-se no sentido de que o Princípio da Proteção Integral trouxe a criança como sujeito de direitos constitucionalmente previstos, com todas as prerrogativas de uma pessoa (sujeito) em condições peculiares de desenvolvimento, preocupando-se com a garantia e segurança de todos os direitos fundamentais.

Por conseguinte, a legislação interna brasileira deixou de visualizar tão somente a questão penal da criança e do adolescente, passando a preocupar-se em garantir a satisfação de todas as necessidades das pessoas em fase de desenvolvimento, assegurando o direito à vida, à educação, à saúde, à liberdade, lazer, conivência familiar e comunitária (CURY et al., 2005, p. 15).

Cury, Garrido e M arçura definem bem essa transformação legislativa trazida através do Princípio da Proteção Integral:

\begin{abstract}
A proteção integral tem como fundamento a concepção de que crianças e adolescentes são sujeitos de direitos, frente à família, à sociedade e ao Estado. Rompe com a idéia de que sejam simples objetos de intervenção no mundo adulto, colocando-os como titulares de direitos comuns a toda e qualquer pessoa, bem como de direitos especiais decorrentes da condição peculiar de pessoas em processo de desenvolvimento (CURY; PAULA; M ARÇURA, 2002, p. 21).
\end{abstract}

Pode-se concluir, portanto, que este princípio aborda a necessidade de garantir à criança os direitos fundamentais que Ihe são inerentes como pessoa em condição especial de desenvolvimento, buscando remover todos os obstáculos que eventualmente surjam neste processo através da adoção de medidas para a defesa de seus interesses.

Em consonância ao Princípio da Proteção Integral, tem-se o Princípio da Prioridade Absoluta, que também busca garantir os direitos da criança como pessoal em peculiar condição de desenvolvimento. 
Do princípio da prioridade absoluta

Este princípio encontra-se no art. 227 da Constituição Federal e está totalmente atrelado ao Princípio da Cooperação, sobre o qual se deve falar primeiramente.

O Princípio da Cooperação foi introduzido em nosso ordenamento jurídico pela Constituição Federal, baseada na Declaração Universal dos Direitos da Criança e do Adolescente. Além disso, está previsto no Estatuto da Criança e do Adolescente em seu art. 4ำ, que dispõe, ex vi:

É dever da família, da comunidade, da sociedade em geral e do Poder público assegurar, com absoluta prioridade, a efetivação dos direitos referentes à vida, à saúde, à alimentação, à educação, ao esporte, ao lazer, à profissionalização, à cultura, à dignidade, ao respeito, à liberdade e à convivência familiar e comunitária. $[\ldots]$

A cooperação corresponde ao trinômio família, comunidade e Estado como responsáveis por assegurar os direitos da criança, ou seja, a pessoa em fase de desenvolvimento deve ser protegida tanto pela família, pela sociedade como um todo quanto pelo Estado.

A responsabilidade pelo desenvolvimento sadio físico e psíquico da criança deve ser observada pela família. Quando esta não possui ou não demonstra meios suficientes para provê-la, surge a responsabilidade do Estado em prover o propício crescimento dessa criança.

Ainda, é necessário destacar a importância (e o dever) de atuação da comunidade, em especial através das organizações não-governamentais, entidades filantrópicas e outras formas de organizações civis.

O importante é entender que a família, o Estado e a sociedade são responsáveis de forma igualitária por tudo o que diz respeito à criança, seja a seus direitos, deveres, desenvolvimento e formação.

Assim, junto a esse princípio da cooperação entre família, Estado e sociedade, o princípio da prioridade coloca a criança como sujeito de direitos privilegiados, cuja segurança é dever de todos.

Quando os sujeitos de direitos tratados são crianças portadoras de deficiência, esse princípio deve-se mostrar ainda mais enfático, uma vez que somente 0 atendimento integral 
e de forma priorizada da criança é que assegurará a passagem para a vida adulta com qualidade de vida e dignidade.

Deve-se ressaltar que essas crianças dependem de cuidados intensivos, como já foi dito anteriormente. Assim, o atendimento prioritário do portador de necessidades especiais deve ocorrer de forma mais abrangente possível para que se miniminize os efeitos nocivos que decorrem da falta de cuidados destinados a preservar a saúde e qualidade de vida dessas crianças.

\section{Estatuto da criança e do adolescente}

A Constituição Federal de 1988 representou o início do chamado Estado Social e Democrático de Direito no Brasil e alguns valores foram sobressaltados, como o respeito à dignidade e aos direitos fundamentais da pessoa humana. A partir de então, restou patente como dever do Estado e como dever da sociedade civil a garantia e observância desses direitos.

Em conseqüência das idéias democráticas expressas no texto constitucional, apresentou-se, urgente, a necessidade de ampliação, aprofundamento e garantia dos direitos dos cidadãos, surgindo, assim, a demanda sobre a inclusão da criança e do adolescente como sujeitos de direitos.

0 resultado da longa luta e pressão dos movimentos de defesa dos direitos da criança e do adolescente foi a promulgação da Lei Complementar no. 8.069/90, em 13 de julho de 1990, o "Estatuto da Criança e do Adolescente", que estabelece, dentre outras coisas, o dever da família, da sociedade e do Estado na garantia da qualidade de vida à infância e à adolescência.

Essa nova legislação ainda incorporou a chamada "Doutrina da Proteção Integral", colocando jovens e crianças como prioridade absoluta dentro de um novo modelo de estrutura e gerenciamento das políticas públicas a eles destinadas.

O Estatuto da Criança e do Adolescente é instituto de normas materiais e processuais, civil, penal e trabalhista, pois regulamenta desde os direitos e deveres da criança e do adolescente até as questões processuais, descrevendo tipos penais, delineando a atuação do Estado, do Ministério Público, da família e da sociedade na vida da população infanto-juvenil, bem como regrando procedimentos como o da adoção, por exemplo. 
Além disso, também buscou regulamentar a efetividade dos direitos fundamentais destinados à população infanto-juvenil, garantindo os meios legais para a sua realização, pormenorizando as ações judiciais necessárias para sua concretização.

Vale relembrar que a prioridade no atendimento às crianças e aos adolescentes foi introduzida no ordenamento jurídico brasileiro pela Constituição Federal de 1988, mas foi delineada e aprimorada com a elaboração da Lei №. 8069/90, que estabelece o Princípio da Proteção Integral logo em seu artigo 1o, e em seu artigo 4ำenfatiza o Princípio da Prioridade; princípios constitucionais que visam proteger a qualidade de pessoa em desenvolvimento das crianças dos ado lescentes.

Destarte, pode-se afirmar, com destreza, que o Estatuto da criança e do Adolescente é importante instituto na garantia dos direitos da criança, mormente daquelas portadoras de necessidades especiais, umas vez que, em se tratando de legislação complementar, buscou salvaguardar todos os preceitos constitucionais que visam proteger a condição peculiar de pessoa em desenvolvimento da criança, em especial daquela portadora de necessidades especiais.

A condição da criança portadora de deficiência, que será abordada no próximo tópico de forma aprofundada, é delicada e requer total aplicação do que dispõe o Estatuto da Criança e do Adolescente.

\section{Da criança portadora de deficiência}

\section{Conceito}

É de importância relevante a este trabalho conceituar a pessoa portadora de deficiência para que se possa abordar o tema "criança portadora de deficiência".

0 que define a pessoa portadora de deficiência não é a falta de um membro nem a visão ou audição reduzidas. 0 que caracteriza a pessoa portadora de deficiência é a dificuldade de se relacionar, de se integrar na sociedade. 0 grau de dificuldade de se relacionar, de se integrar na sociedade. 0 grau de dificuldade para a integração social é que definirá quem é ou não portador de deficiência. (ARAÚJ0, op cit.)

A Declaração dos Direitos das Pessoas Deficientes também conceituou pessoa portadora de deficiência: 
0 termo 'pessoas deficientes' refere-se a qualquer pessoa incapaz de assegurar por si mesma, total ou parcialmente, as necessidades de uma vida individual ou social normal, em decorrência de uma deficiência, congênita ou não, em suas capacidades físicas ou mentais.

No Brasil, o Decreto no 914/1993 considerou em seu artigo 3ำ que a pessoa portadora de deficiência é aquela que apresenta, em caráter permanente, perdas ou anormalidades de sua estrutura ou função psicológica, fisiológica ou anatômica, que gerem incapacidade para o desempenho de atividade, dentro do padrão considerado normal para 0 ser humano.

A criança portadora de deficiência, enquadrando-se em todos esses conceitos merece primordial atenção, pois, qualquer criança tem suas atividades limitadas à supervisão e dependência de um responsável, muito mais dependente é aquela portadora de necessidades especiais, pelo que sua proteção e a proteção de seus direitos são oportunamente predilecionados pela legislação brasileira.

Dos direitos da criança portadora de deficência

A primeira manifestação em relação aos direitos da Criança deu-se em 1924, com a Declaração de Genebra sobre os Direitos da Criança, mas, de forma efetiva, ocorreu em 20 de novembro de 1959, pela Assembléia Geral das Nações Unidas, com a elaboração da Declaração Universal dos Direitos da Criança.

Essa Declaração é composta por 10 princípios que deram início á preocupação com a criança, em destaque à sua peculiar condição de pessoa em desenvolvimento.

Importante mencionar cada um dos princípios elencados na Declaração de 1959 por fundamentarem toda a legislação pátria brasileira que regulamenta os direitos da criança. 0 primeiro princípio é o princípio da igualdade sem distinção de raça, religião ou nacionalidade, que garante o desfrute de todos os direitos previstos na Declaração por todas as crianças, indistintamente.

O segundo princípio é o que embasa o Princípio da Proteção Integral, e garante à criança o direito à especial proteção para o seu desenvolvimento físico, mental e social. 0 terceiro princípio garante o direito a um nome e uma nacionalidade desde o nascimento. 


\section{Os direitos da criança portadora de deficiência e o benefício assistencial de prestação continuada}

Em seguida, o princípio IV assegura o direito à alimentação, moradia, e assistência médica adequadas para a criança e também para a sua mãe. Este quarto princípio garante ainda que a criança terá direito aos benefícios da previdência social.

0 quinto princípio, destaque deste estudo, garante 0 direito a educação e a cuidados especiais para a criança física ou mentalmente deficiente, devendo ser observado cada caso em particular para que receba um tratamento específico.

0 sexto princípio trata do direito ao amor e à compreensão por parte dos pais e da sociedade, onde já se verifica a base do princípio da cooperação, em que a responsabilidade pelas crianças é repartida entre família, sociedade e o Estado, já que referido princípio estabelece que "a sociedade e as autoridade públicas terão a obrigação de cuidar especialmente do menor abandonado ou daqueles que careçam de meios adequados de subsistência".

O sétimo princípio garante o direito à educação gratuita e ao lazer infantil, devendo estes direitos tornarem-se 0 interesse diretor de seus responsáveis, destacando a educação com qualidade que lhes assegure o desenvolvimento de aptidões individuais, em condições de igualdade de oportunidade.

0 oitavo princípio traduz-se no que chamamos de Princípio da Prioridade, pois estabelece o direito de socorro em primeiro ligar em casos de catástrofes.

0 penúltimo princípio assegura 0 direito à proteção contra 0 abandono e a exploração do trabalho, observando a qualidade de pessoa em desenvolvimento da criança e considerando que 0 trabalho antes de uma idade mínima pode prejudicar a saúde, a educação e o desenvolvimento físico, mental ou moral da criança. 0 décimo e último princípio garante o direito a crescer dentro de um espírito de solidariedade, compreensão, amizade e justiça entre os povos.

Trinta anos após a Declaração Universal dos Direitos da Criança, em 20 de novembro de 1989 as Nações Unidas adotadoram a Convenção sobre os Direitos da Criança, que foi concebida em razão da necessidade de garantir a proteção e cuidados especiais à criança, incluindo proteção jurídica apropriada, em virtude de sua condição peculiar de pessoa em desenvolvimento.

0 escopo era incentivar os países membros a programar o desenvolvimento pleno e harmônico da personalidade de suas crianças, favorecendo o seu crescimento em ambiente 
familiar, em clima de felicidade, amor e compreensão, preparando-as de forma plena para a vida individual dentro da sociedade.

Essa carta, que ainda definiu que "criança é todo ser humano com menos de 18 (dezoito) anos", ressalvando as leis nacionais que previssem a maioridade alcançada antes desta idade, foi ratificada e promulgada, no Brasil, pelo Decreto $n^{\circ} 99.710$, de 21 de novembro de 1990.

A legislação brasileira ainda prevê a garantia de todos os direitos elencados por Declarações internacionais na própria Constituição Federal e no Estatuto da Criança e do Adolescente.

Pode-se concluir este tópico afirmando que a legislação específica e o próprio Princípio da Igualdade garantem à criança portadora de deficiência os direitos que asseguram o respeito à condição peculiar de pessoa em desenvolvimento.

Portanto, importante ter em mente que a criança portadora de deficiência possui uma condição de desenvolvimento muito desfavorável em relação a crianças que não são portadoras de necessidades especiais e, ante ao princípio da igualdade, em especial, a concessão do benefício sobre o qual se discorrerá a seguir é de extrema importância para que os direitos dessas crianças sejam garantidos.

\section{Benefício assistencial à criança portadora de deficiência}

O benefício de prestação continuada é garantido à pessoa portadora de deficiência pelo artigo 203, V da Constituição Federal Brasileira e pelo artigo 20 da Lei no 8.742/93 - Lei Orgânica de Assistência Social.

Este benefício tem caráter continuado, pois é devido mensal e sucessivamente (M ARTINS, 2007). Além disso, não tem caráter de seguro social, pois para que seja concedido não é necessário que haja contribuição para a seguridade social; basta que haja a comprovação dos requisitos legais que serão abordados mais adiante.

É de extrema importância para a assistência social da criança portadora de deficiência a existência de um benefício como este. Sabe-se que dentro da realidade social brasileira o salário mínimo nacional não garante o disposto no inciso IV do artigo 70 da Constituição Federal. Portanto, para famílias carentes a concessão deste benefício pode significar uma expectativa de melhora na vida da criança portadora de deficiência. 
Requisitos

Este benefício deverá ser requerido administrativamente perante o Instituto Nacional do Seguro Social - INSS.

Como o Instituto concede os benefícios de forma absolutamente legalista, observando apenas os requisitos estabelecidos em lei, sem adentrar à análise de cada caso concreto e verificar a aplicação de princípios e direitos fundamentais, muitas vezes se faz necessária a corrida ao Poder Judiciário para que este determine ao INSS que conceda o benefício, através de uma análise aprofundada do caso concreto, dos princípios norteadores da assistência social e de todo 0 ordenamento jurídico.

Os requisitos para a concessão do benefício à pessoa portadora de deficiência estão previstos nos parágrafos $2^{\circ}$ e $3^{\circ}$ do artigo 20 da Lei Orgânica de Assistência Social, são eles:

$\S 2$ Para efeito de concessão deste benefício, a pessoa portadora de deficiência é aquela incapacitada para a vida independente e para o trabalho.

§ 3o Considera-se incapaz de prover a manutenção da pessoa portadora de deficiência ou idosa a família cuja renda mensal per capita seja inferior a 1/4 (um quarto) do salário mínimo.

Assim, destacam-se dois requisitos: a incapacidade para a vida independente e para o trabalho e a miserabilidade, caracterizada na família cuja renda per capta seja inferior a $1 / 4$ do salário mínimo vigente.

A questão da incapacidade será verificada por perícia médica a ser realizada pelo Instituto Nacional de Seguridade Social - INSS, que constatará ou não a existência de deficiência que impeça ou limite a incapacidade para os atos da vida independente e para 0 trabalho.

Quanto à questão da criança, esta é presumidamente incapaz para o trabalho, por existência de vedação legal (artigo 70ㅡ, XXXIII da Constituição Federal). É preciso lembrar, porém, que a criança portadora de deficiência necessita de cuidados intensivos para um desenvolvimento sadio, já que muitas vezes necessitam de terapias específicas, como fisioterapia, fonoterapia, entre outras.

Esses cuidados geralmente são dispensados por um ente do grupo familiar que abdica do trabalho remunerado para que possa auxiliar e amparar a criança portadora de necessidades especiais. Consequentemente, a abdicação do trabalho remunerado resulta no 
agravamento das dificuldades financeiras da família carente, prejudicando a qualidade de vida da criança que exige cuidados especiais.

Assim, a criança não pode trabalhar e o ente do grupo familiar deixa de fazê-lo para assegurar que a criança não fique desamparada, ou seja, de uma forma ou de outra a deficiência da criança impede o exercício de trabalho remunerado gerando uma insuficiência de renda familiar, o que já seria suficiente para a concessão d benefício em questão.

Portanto, em que pese a lei refira-se à incapacidade para a vida independente $\mathbf{e}$ para o trabalho, o entendimento jurisprudencial tem sido no sentido de que é perfeitamente possível a concessão do benefício de prestação continuada à criança portadora de deficiência, atendendo a um requisito ou outro.

Assim, quanto ao requisito da deficiência, basta que se comprove a sua existência e a conseqüente limitação para os atos da vida comum.

O segundo requisito, o da miserabilidade, comprovada pela família cuja renda per capita seja inferior a $1 \frac{1}{4}$ do salário mínimo vigente, merece discussão mais aprofundada, pois já foi objeto de Ação Direta de Inconstitucionalidade.

Primeiramente, é necessário esclarecer como é composto o grupo familiar para que se possa obter o valor da renda per capita.

De acordo com o parágrafo 10 do artigo 20 da lei ํㅜ 8.742/93, "entende-se como família o conjunto de pessoas elencadas no art. 16 da Lei no 8.213, de 24 de julho de 1991, desde que vivam sob o mesmo teto".

Por sua vez, 0 artigo 16 da Lei № 8.213/91 dispõe sobre os beneficiários do Regime Geral de Previdência Social como dependentes do segurado, e os elenca em seus três incisos.

Definido o grupo familiar, adentra-se à questão do requisito da renda per capita. A lei é clara ao estabelecer que o benefício de prestação continuada somente será concedido àquele que comprovar renda per capita familiar inferior a $1 / 4$ do salário mínimo vigente (parágrafo 3o do artigo 20 da Lei Orgânica de Assistência Social - Lei no 8.742/93).

Porém, esse limite foi questionado pelo que dispõe o inciso IV do artigo $7^{\circ} \mathrm{da}$ Constituição Federal, que orienta o que deve refletir a fixação do salário mínimo. 
Assim, a discussão iniciou-se por considerarem, alguns tribunais, inconstitucional a concessão do benefício apenas àqueles cuja renda familiar fosse inferior a $1 / 4 \mathrm{de}$ salário mínimo, já que o mínimo deveria garantir todo o previsto no citado inciso IV do artigo 70 da Constituição.

A controvérsia foi decidida pela Adln no 1.232-1, com resultado publicado em 01/06/2001 no Diário da Justiça. O Supremo Tribunal Federal considerou 0 § 3o do artigo 20 da Lei no 8.742/93 constitucional e posicionou-se no sentido de que a lei traz a hipótese objetiva de prestação assistencial do Estado. O Superior Tribunal de Justiça, responsável por dar interpretação à Lei Federal, tem se posicionado da mesma forma, definindo que o mencionado $§ 3^{\circ}$ estabelece um limite objetivo para a concessão do benefício, pois, para a família cuja renda per capita é inferior a 1/1\% do salário mínimo, a miserabilidade é presumida, o que não impede a análise de outros meios de prova em cada caso concreto.

Os Tribunais têm considerado que, para o cálculo do valor da renda per capita familiar deve-se descontar da renda total auferida os valores gastos com o sustento da família para depois dividir esta diferença pelo número de integrantes do grupo familiar e obter o valor final da renda per capita.

Delineados os dois requisitos legais e analisando as divergências que surgiram ao longo da aplicação da LOAS, pode-se notar que o poder Judiciário tem aplicado princípios como o da dignidade da pessoa humana para a justificar a concessão do benefício assistencial.

\section{Da eficácia do benefício de prestação continuada}

(In)aplicabilidade do inciso $\mathrm{V}$ do artigo $4 \underline{0}$ da lei orgânica de assistência social e os critérios utilizados pela autarquia previdenciária

Prevê como princípio da assistência social o inciso V do artigo 4ํㅡ da Lei nํ 8.742/93:

$[\ldots]$ divulgação ampla dos benefícios, serviços, programas e projetos assistenciais, bem como dos recursos oferecidos pelo Poder Público e dos critérios para sua concessão.

Porém, não se verifica o cumprimento deste princípio, uma vez que pouco de sabe a respeito do benefício assistencial. 
A referência que se tem, inclusive entre o meio acadêmico, é a respeito de um benefício concedido ao idoso, que muitos chegam a chamar de aposentadoria, tanto o é que, comumente, os beneficiários do amparo assistencial dizem que são aposentados, o que se trata de um equívoco, posto que a aposentadoria corresponde a um benefício previdência com natureza de seguro social e não de assistência social.

Pode-se dizer que as informações relacionadas à concessão do benefício a crianças é ainda menor. Esse fato pode ser observado durante a pesquisa jurisprudencial. Quando o assunto é a concessão do benefício assistencial de prestação continuada ao idoso ou ao portador de deficiência encontra-se um grande banco de dados disponível nos sites dos Tribunais Federais e Estaduais. Entretanto, quando a pesquisa delimita-se à concessão do referido benefício à criança portadora de deficiência encontra-se poucas decisões a respeito.

Para que se cumpra com efetividade o objetivo do benefício assistencial é necessário que haja ampla divulgação de sua existência, que os Municípios junto aos Conselhos Tutelares travem campanhas tornando pública a possibilidade de concessão do benefício junto às próprias entidades que proporcionam atendimento especial à criança portadora de deficiência, como a APAE (Associação de Pais e Amigos dos Excepcionais) e os Institutos Educacionais que se espalham pelo país.

Além do desconhecimento acerca da existência desse benefício assistencial, um outro fator dificulta que o mesmo chegue às famílias que dele necessitam: o legalismo excessivo da Autarquia Previdenciária, que restringe a concessão aos casos que se amoldam perfeitamente ao que a Lei requisita. Não há interdisciplinaridade entre as decisões da Autarquia Previdenciária e os princípios constitucionais, bem como com o Estatuto da Criança e do Adolescente.

0 critério da miserabilidade é analisado somente sob o critério objetivo, sem levar em consideração as condições que se apresentam em cada caso concreto.

Judicialmente, o INSS tem sustentado a tese de que o benefício só poderá ser concedido à criança portadora de deficiência se restar comprovado que ela depende de cuidados especiais que impossibilitem um dos membros do grupo familiar de exercer atividade remunerada.

Tal argumento improcede ante aos próprios princípios da proteção integral e da prioridade, pois, se ao adulto é conferido o benefício, muito mais necessário se faz à criança, 


\section{Os direitos da criança portadora de deficiência e o benefício assistencial de prestação continuada}

que além de estar em fase de desenvolvimento físico e psicológico, sofre de algum tipo de deficiência.

Além disso, configurada a miserabilidade, seja dentro do critério objetivo ou subjetivo, é imperativa a concessão do benefício independente do responsável pela criança exercer atividade laborativa, primeiro porque a criança portadora de necessidades especiais precisa de variados tipos de tratamentos, o que requer gastos e segundo porque os responsáveis precisam trabalhar para a busca do sustento familiar.

Portanto, a eficácia do benefício em questão vai além do que diz respeito ao seu valor pecuniário e o auxílio que representa no orçamento familiar, adentra à questão dos critérios de sua concessão, da aplicabilidade dos princípios que protegem a criança, em especial a portadora de deficiência e à questão de sua divulgação, uma vez que o benefício existe, mas não tem chegado às famílias que dele verdadeiramente necessitam.

\section{Conclusão}

Os direitos da criança portadora de deficiência estão amplamente protegidos pela Constituição Federal e legislação infra-constitucional.

0 direito à vida, à saúde, à liberdade e à igualdade estão garantidos como nunca foram em tempos remotos.

Os princípios constitucionais da Proteção Integral e da Prioridade Absoluta, que garantem 0 atendimento primordial à criança, mormente à portadora de necessidades especiais, trouxeram a responsabilidade pelo desenvolvimento da população infantil divida entre a família, o Estado e a sociedade, o que enfatiza a importância dos direitos da criança.

0 Estatuto da Criança e do Adolescente, Lei №. 8069/90, reforçou os princípios trazidos pela Constituição Federal, assegurando à criança todos os seus direitos desde 0 tratamento perinatal.

Tudo isso foi possível pela inovação do Estatuto que posicionou a criança e o adolescente como sujeitos de direitos, deixando o antigo conceito esculpido no Código de Menores.

Verificou-se os tipos de deficiência que podem acometer uma criança e as dificuldades diárias que elas e suas famílias enfrentam, especialmente aquelas carentes de recursos financeiros. 
Para suprir essas carências, encontra-se a assistência social garantida constitucionalmente, cujo principal objetivo é a erradicação da pobreza e que proporciona a concessão de benefício assistencial à criança portadora de deficiência.

Este benefício surge como uma possibilidade de melhorar a qualidade de vida da criança portadora de necessidades especiais inserida em família carente, pois, em que pese seja no valor de um salário mínimo, busca assegurar tratamento adequado à deficiência e os cuidados mínimos pelo ente do grupo familiar que muitas vezes deixa de exercer uma atividade remunerada para auxiliar a criança deficiente nos tratos do dia-a-dia.

Como a concessão do benefício exige o enquadramento de dois requisitos previstos na lei que o regulamenta, muitos pedidos de concessão têm chegado ao poder judiciário, já que o INSS, responsável pela concessão, analisa os casos de forma estritamente legal, sem considerar as condições que cada situação concreta requer.

O posicionamento jurisprudencial, inclusive, já derrubou um dos requisitos legais, devendo sua aplicação ser analisada no caso concreto levando-se em consideração os princípios da dignidade da pessoa humana, do direito à vida e à saúde.

Em que pese todas essa garantias e a existência de um benefício assistencial, a realidade das famílias carentes no nosso país está muito distantes, pois não há conhecimento desses direitos, pois são divulgados de forma tímida ou não são divulgados.

Verificam-se, na mídia, propagandas a respeito dos programas que envolvem 0 programa Fome Zero, como a bolsa-família e outros auxílios assistências, que consistem em meras medidas eleitoreiras. Tanto o é que não se vê, por exemplo, propagandas incentivando famílias carentes à procura pelo Instituto Nacional de Seguridade Social para que recebam o benefício assistencial de prestação continuada.

Portanto, as leis que asseguram os direitos à população carente de um modo geral, em especial às famílias em que um dos integrantes é uma criança portadora de deficiência, estão muito longe da realidade social brasileira.

Em que pese o Poder Judiciário tenha atuado na proteção desses direitos, é preciso que sejam não só garantidos, mas esclarecidos antes mesmo de chegar à Justiça, o que poderia ocorrer através de políticas que visem à divulgação dos serviços e benefícios assistenciais prestados pelo Estado. 
Cumprido o objetivo principal deste artigo, que se traduz em verificar e analisar os direitos da criança portadora de deficiência e a importância do benefício assistencial de prestação continuada às famílias carentes, pode-se concluir que ainda há um longo caminho a ser percorrido na efetivação de todos os direitos fundamentais garantidos ao ser humano, para que tenha uma vida com condições mínimas de dignidade.

\section{Referências}

ARAÚJO, Luiz Alberto David. A proteção constitucional das pessoas portadoras de deficiência. Brasília: Coordenadoria Nacional para Pessoa Portadora de Deficiência, 1997.

COIMBRA, Feijó. Direito Previdenciário Brasileiro. 4. ed. Rio de Janeiro: Edições Trabalhistas, 1993.

CURY, M unir et al. Estatuto da Criança e do Adolescente Comentado. 7. ed. São Paulo: Malheiros Editores, 2005.

CURY, M unir; PAULA, Paulo Afonso Garrido de; M ARÇURA, Jurandir Norberto. Estatuto da Criança e do Adolescente Anotado. 2. ed. São Paulo: Revista dos Tribunais, 2002.

M ARTINS, Sérgio Pinto. Direito da Seguridade Social. 24. ed. São Paulo: Atlas, 2007.

PINHO, Rodrigo César Rebello. Teoria Geral da Constituição e Direito Fundamentais. 8. ed. São Paulo: Saraiva, 2008.

SILVA, José Afonso da. Curso de Direito Constitucional Positivo. 24. ed. São Paulo: Malheiros Editores, 2005.

SILVA, Paulo Napoleão Nogueira da. Curso de direito Constitucional. 3. ed. Rio de Janeiro: Editora Forense, 2003.

VERONESE, Josiane Rose Petry. Direito da Criança e do Adolescente. Florianópolis: OAB/SC Editora, 2006. 